\title{
ASO Visual Abstract: Preoperative Cardiopulmonary Exercise Test Associated with Postoperative Outcomes for Patients Undergoing Cancer Surgery-A Systematic Review and Meta- Analyses
}

Daniel Steffens, $\mathbf{P h D}^{1,2}$ @ , Hilmy Ismail, $\mathrm{MD}^{3,4}$, Linda Denehy, $\mathbf{P h D}^{3,4}$, Paula R. Beckenkamp, $\mathbf{P h D}^{5}$, Michael Solomon, DMed ${ }^{1,2}$, Cherry Koh, PhD ${ }^{1,2}$, Jenna Bartyn, $\mathrm{MPH}^{1}$, and Neil Pillinger, MB, BCh ${ }^{1,2}$

${ }^{1}$ Surgical Outcomes Research Centre (SOuRCe), Royal Prince Alfred Hospital (RPAH), Sydney, NSW, Australia; ${ }^{2}$ Faculty of Medicine and Health, Central Clinical School, The University of Sydney, Sydney, Australia; ${ }^{3}$ School of Health Sciences, The University of Melbourne, Melbourne, Australia; ${ }^{4}$ Peter MacCallum Cancer Centre, Melbourne, Australia; ${ }^{5}$ Faculty of Health Sciences, Discipline of Physiotherapy, The University of Sydney, Musculoskeletal Health, Sydney, Australia

Use of a cardiopulmonary exercise test (CPET) during the preoperative period is increasing. This systematic review and meta-analyses demonstrated significant associations between preoperative CPET values and postoperative surgical outcomes (https://doi.org/10.1245/s10434-021-10251-3).
Publisher's Note Springer Nature remains neutral with regard to jurisdictional claims in published maps and institutional affiliations.

DISCLOSURE There are no conflicts of interest.

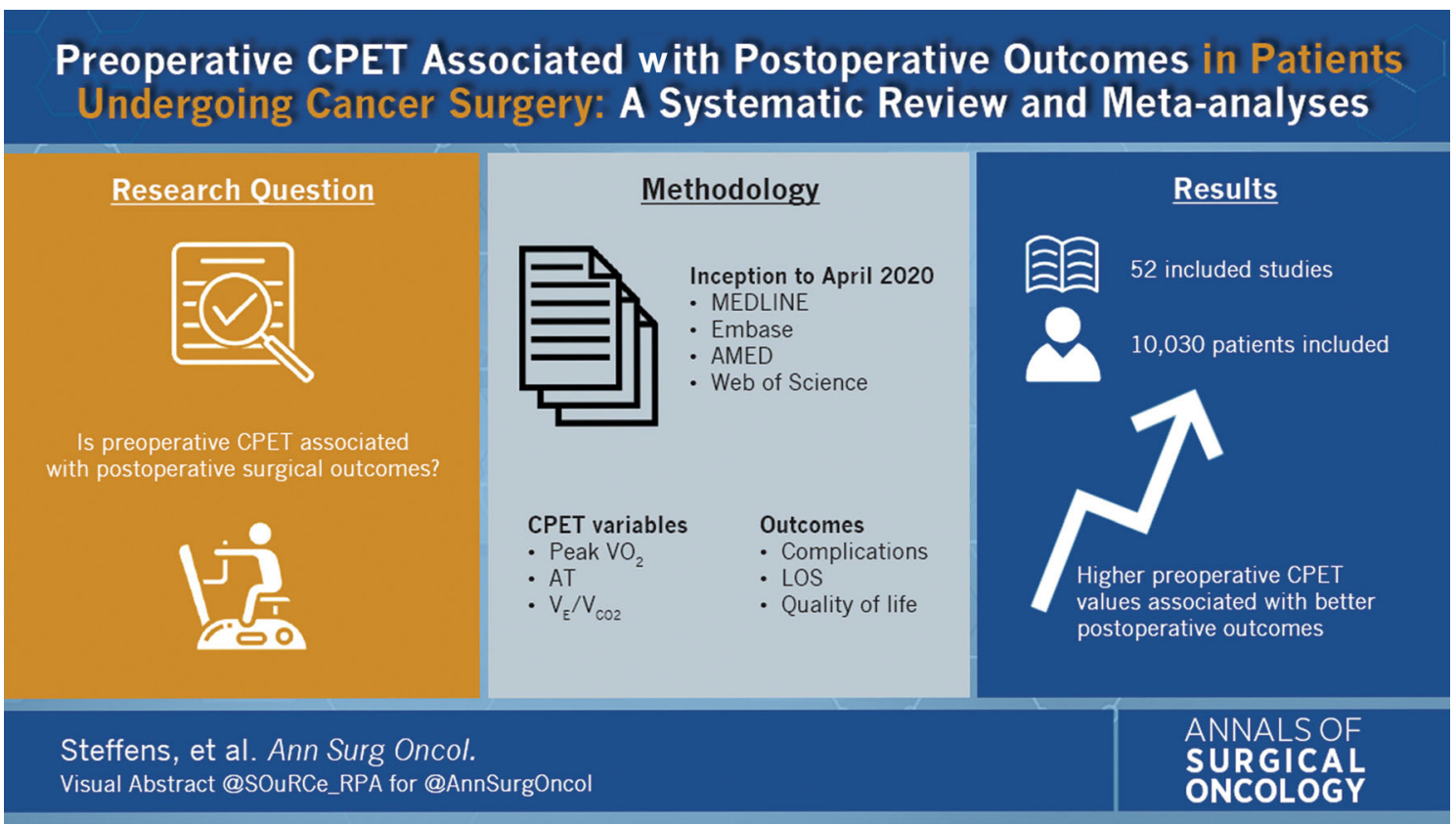

(C) Society of Surgical Oncology 2021

Published Online: 29 June 2021

D. Steffens, $\mathrm{PhD}$

e-mail: daniel.steffens@health.nsw.gov.au 